\title{
Bacterial vaginosis and adverse outcomes among full-term infants: a cohort study
}

Adam S. Dingens ${ }^{1,2,3^{*}+}$, Tessa S. Fairfortune ${ }^{1 \dagger}$, Susan Reed ${ }^{1,3,4}$ and Caroline Mitchell ${ }^{5,6}$

\begin{abstract}
Background: Bacterial vaginosis (BV) during pregnancy is a well-established risk factor for preterm birth and other preterm pregnancy complications. Little is known about adverse neonatal outcomes associated with BV exposure in full-term births, nor its influence on adverse outcomes independent of its effect on gestational age. The purpose of this study was to examine the relationship between BV during pregnancy and adverse neonatal outcomes among full-term and preterm infants.

Methods: We conducted a retrospective cohort study of Washington State mother/infant pairs from 2003-2013, stratified by full-term (primary outcomes) and preterm births (secondary outcomes). BV-exposed and unexposed women were frequency-matched based on year of delivery. BV exposure and adverse outcomes [assisted ventilation/respiratory distress, neonatal intensive care unit (NICU) admission, neonatal sepsis, fetal mortality, and infant mortality] were identified using birth certificates, ICD-9 codes from linked hospital records, and death certificates. Associations between BV exposure and outcomes were assessed using multivariable Poisson regression, adjusted for maternal demographics, gestational age, and other pregnancy complications, including infections.

Results: A total of 12,340 mother/infant pairs were included: 2,468 BV-exposed (2198 term, 267 preterm) and 9,872 BV unexposed (9156 term, 708 preterm). Among full-term infants, BV-exposed mothers were younger, more likely to be Black or Hispanic, more likely to have had a sexually transmitted infection, and less likely to have a college degree than unexposed mothers. Term BV exposed infants were more likely to have meconium at delivery. Following adjustment, BV was associated with an increased risk of assisted ventilation/respiratory distress at birth $(\mathrm{aRR}=1.28,95 \% \mathrm{Cl} 1.02-1.61)$, NICU admission ( $\mathrm{aRR}=1.42,95 \% \mathrm{Cl} 1.11-1.82)$, and neonatal sepsis (aRR $=1.60,95 \%$ Cl 1.13-2.27) among full-term infants. These associations were independent of the presence of chorioamnionitis or meconium. Among preterm infants, BV-exposure was associated with an increased risk for NICU admissions only (aRR $=1.24,95 \% \mathrm{Cl} 1.04-1.46)$.
\end{abstract}

Conclusions: BV exposure during pregnancy is associated with adverse neonatal outcomes even among infants born full-term. These findings amongst full-term infants are novel, and highlight neonatal implications of BV in pregnancy independent of BV's effect on preterm birth.

Keywords: Bacterial vaginosis, Term, Adverse neonatal outcomes, Neonatal sepsis

\footnotetext{
* Correspondence: adingens@uw.edu

${ }^{\dagger}$ Equal contributors

'Department of Epidemiology, University of Washington School of Public Health, 1959 NE Pacific Street Health Sciences Bldg, Seattle, WA 98195, USA

¿University of Washington, Molecular \& Cellular Biology Program, 1959 NE

Pacific St, Seattle, WA 98195, USA

Full list of author information is available at the end of the article
} 


\section{Background}

Bacterial vaginosis (BV), defined as a disturbance in the natural vaginal microbiota characterized by reduced Lactobacillus and overgrowth of anaerobic bacteria [1], is found in $9 \%$ to $23 \%$ of pregnant women [2]. Symptoms include vaginal discharge and malodor, but often women who have BV are asymptomatic. BV during pregnancy is an established risk factor for preterm delivery [1, 3-5] as well as other adverse preterm pregnancy outcomes such as premature rupture of membranes, low birth weight, chorioamnionitis, and spontaneous abortion [1, 4, 5]. A single cohort study of preterm infants suggests that BV is associated with an increased risk of adverse neonatal outcomes including: NICU admission, respiratory distress at birth, requirement of assisted ventilation at birth, and NICU stays lasting longer than 2 days [6]. Data on adverse neonatal outcomes associated with $\mathrm{BV}$ among infants born full-term is almost nonexistent.

We hypothesized that BV is associated with an increase in adverse neonatal outcomes due to ascending infection at all gestational ages and that the increased risks previously observed among preterm pregnancies are not solely attributable to prematurity. The primary aim of this large Washington State cohort study was to evaluate, among full-term infants, the effects of BV on five fetal/infant outcomes: assisted ventilation/respiratory distress at birth, admission to neonatal intensive care unit (NICU), neonatal sepsis, fetal mortality, and infant mortality. Our secondary aims were to evaluate these same outcomes among preterm $(<37$ weeks gestation) infants exposed and unexposed to $\mathrm{BV}$, as well as to reaffirm the relationship between BV and preterm delivery among all infants. Women included as BV-exposed in our study were likely symptomatic women, and asymptomatic women were likely disproportionately misclassified in the unexposed group. However, this misclassification would only drive findings toward the null - any association found in our study would be perhaps, "only the tip of the iceberg", or a marker for an important underlying etiology related to BV but not directly causal.

\section{Methods}

We conducted a population-based retrospective cohort study using data from Washington State birth certificates and birth hospitalizations from 2003-2013. These data were extracted from the Birth Events Records Database (BERD), a database linking more than $95 \%$ of Washington State birth certificate data with maternal and infant hospitalization records from the statewide Comprehensive Hospital Abstract Report System (CHARS) [7]. Infant mortality was identified from death certificates issued through 2014. While there is underreporting of birth complications and maternal conditions on birth certificates [8], the use of hospital discharge and death certificate data improves the accuracy and completeness of both exposures and outcomes in this study. Four of our 5 outcomes: assisted ventilation/respiratory distress at birth, admission to neonatal intensive care unit (NICU), fetal mortality, and infant mortality are "hard outcomes" and it is highly unlikely that they would be inaccurate. Neonatal sepsis, our fifth outcome, is perhaps more prone to inaccurate birth certificate reporting [8], but it is also likely to be captured in linked hospital discharge data, as the sensitivity of ascertaining infection-related outcomes using ICD9 codes is near perfect [9]. All data were de-identified, and the study was determined to be exempt from review by the Washington State Institutional Review Board.

\section{Study population}

We included all BV-exposed mothers who gave birth in Washington State from 2003-2013 who met study criteria. Women were considered BV-exposed if on the birth certificate the "other" box under "Infections Present and/or Treated During this Pregnancy" was checked and the write-in space specified the infection as bacterial vaginosis (e.g., "BV", "Bac Vag", or "B Vaginosis"). Additional exposed women were identified using ICD-9 codes 616.10, 616.11, and 646.63 from CHARS data. BV-unexposed women did not have a write-in infection that could be identified as BV nor any BV ICD-9 codes in their delivery hospitalization records. We enrolled four unexposed women per exposed woman, frequency-matched for the infant's year of birth. Non-singleton and births with a congenitally malformed infant were excluded.

\section{Primary outcome measures}

We measured the risk of five fetal/infant outcomes: assisted ventilation/respiratory distress at birth, NICU admission, neonatal sepsis, fetal mortality, and infant mortality. Outcomes were identified using a combination of birth certificate checkboxes, ICD-9 codes from the birth hospitalization record, and death certificates. If either the box on the birth certificate was checked, or the ICD-9 code was present, the outcome was considered to have occurred. Assisted ventilation/respiratory distress is coded on the birth certificate as "assisted ventilation required immediately following birth" and was also evaluated using ICD-9 codes 768.5 (severe birth asphyxia) and 769 (respiratory distress syndrome in a newborn). NICU admission was identified via birth certificate checkbox. Neonatal sepsis was ascertained using ICD-9 codes 771.81 (septicemia [sepsis] of newborn) and 771.83 (bacteremia of newborn) and by birth certificate checkbox. Because this study primarily used birth certificate data, fetal deaths before 20 weeks gestation (where no birth or death certificate would have been issued) were not captured. Fetal mortality at 20 weeks or greater gestation was identified from birth hospitalization records, ICD-9 
code V27.1, and linked death certificates. Infant mortality is defined as death within one year of birth, and was identified via linked birth and death certificates.

\section{Statistical analyses}

We used Poisson regression to calculate risk ratios with $95 \%$ confidence intervals for all outcomes among sub-cohorts of full-term infants ( $\geq 37$ weeks gestation) and preterm infants $(<37$ weeks gestation), as well as the complete cohort. Gestational age was established from the birth certificate, primarily from ultrasound dating in the first or second trimester $(N=12,317)$; when this variable was missing, we estimated gestational age using the date of the mother's last menstrual period $(N=23)$. We established a priori that maternal age and maternal race (White, Black, Hispanic, Asian, Native American, Other) would be included in the models $[3,5,10,11]$. We also controlled for gestational age when appropriate.

In addition, we considered the following as covariates: maternal education (<high school, high school graduate/ some college, college degree); delivery method (cesarean delivery or vaginal birth, either spontaneous or assisted); prenatal smoking (yes/no); nulliparity (yes/no); birth weight $<2500$ grams (yes/no); small for gestational age among live born infants (lowest 10th percentile, calculated from the BERD database from 1989-2002 based on Lipsky et al.) [12]; sexually transmitted infection (STI; syphilis, gonorrhea, chlamydia, or genital herpes) diagnosed and/or treated during pregnancy (yes/no); presence of hypertension, diabetes, or pre-eclampsia during pregnancy (yes/no); presence of chorioamnionitis (yes/no); and presence of moderate or heavy meconium (yes/no). Covariates with significant missing data were not included in the models. A variable was considered to be a potential confounder if controlling for the variable produced a $>10 \%$ change in the risk estimate. Confounding was assessed separately in the full-term and preterm sub-cohorts, as well in the entire cohort for all outcomes. Confounders determined not to be in the causal pathway were included in the model. Significant associations between BV and the examined outcomes were further explored with stratified analyses evaluating our hypothesis that poor outcomes were likely to be associated with an ascending infection.

All analyses were conducted using STATA 13 software (Stata Corporation, College Station, Texas).

\section{Results}

We included and analyzed 12,340 mother/infant pairs. Gestational age was missing for 11 infants; these participants were excluded from the full-term $(N=11,354)$ and pre-term $(N=975)$ sub-cohort analyses but were included for analyses of the full cohort. There were 2,198 term and 267 preterm mother/infant pairs identified that were BV exposed.
Demographic characteristics varied between BV exposed and unexposed women (Table 1). Among fullterm birth, BV-exposed mother were significantly younger than unexposed mothers ( $<20$ years: $14.7 \%$ vs. $7.3 \%$ ), and more likely to be having their first birth ( $47.2 \%$ vs. $41.4 \%)$. They were more likely to be Black (10.7\% vs. $4.6 \%)$ or Hispanic (19.0\% vs. $10.8 \%)$, and less likely to have a college degree ( $16.5 \%$ vs. $36.1 \%)$. BV-exposed mothers were more likely to have smoked during pregnancy ( $16.5 \%$ vs. $10.1 \%)$, less likely to have had a cesarean delivery ( $21.7 \%$ vs. $27.1 \%)$, more likely to have a small for gestational age infant $(10.3 \%$ vs. $8.6 \%$ ), less likely to have had at least adequate prenatal care as indicated by the Kotelchuck index $(59.6 \%$ vs. $62.5 \%$ ), and more likely to have had an STI diagnosed and/or treated during their pregnancy ( $13.5 \%$ vs. $4.1 \%)$. Comorbid pregnancy conditions (diabetes, hypertension and preeclampsia) were similar between BV-exposed and BV-unexposed mothers. Term infants born to BV-exposed mothers were more likely to have moderate or heavy meconium (9.0 \% vs. $5.6 \%$ ) than infants of unexposed mothers. Preterm infants born to BV-exposed mothers had a higher risk of chorioamnionitis ( $8.2 \%$ vs. $5.8 \%$ ). Other demographic characteristics were similar in the full-term and preterm births, with the exception that cesarean deliveries and low birth weight infants were higher in the preterm births.

Among full-term infants, BV exposure was significantly and positively associated with an approximately $28 \%$ increased risk of assisted ventilation at birth, a $42 \%$ increased risk for admission to NICU and a $60 \%$ increased risk for neonatal sepsis after adjusting for gestational age, maternal age, and maternal race (Table 2). There was no association with fetal or infant mortality. The presence of an STI confounded the relationship between BV and fetal mortality in the full-term births and was controlled for, but presence of an STI did not confound any other outcomes in term, preterm, or all births. Additionally, no other covariates confounded the relationship between BV and any of the outcomes examined. Among full-term births, the risk ratio for the association of $\mathrm{BV}$ with neonatal sepsis was higher in SGA infants (adjusted risk ratio $[\mathrm{aRR}]=2.57$, $95 \%$ confidence interval $[\mathrm{CI}] 1.04,6.40)$ than in AGA and LGA infants ( $\mathrm{aRR}=1.46,95 \%$ CI 1.00, 2.13), but confidence intervals are overlapping. Rates of chorioamnionitis and meconium were higher in BV-exposed pregnancies, but neither modified the relationship between BV and the outcomes examined (Table 3).

Among preterm infants, BV exposure was associated with a $24 \%$ increased risk for admission to NICU after adjusting for gestational age, maternal age, and maternal race (Table 4). Assisted ventilation at birth, neonatal sepsis, infant and neonatal mortality were not associated with BV exposure. 
Table 1 Maternal characteristics of women with and without bacterial vaginosis during pregnancy, Washington State $2003-2013$

\begin{tabular}{|c|c|c|c|c|c|c|c|c|c|c|c|c|}
\hline & \multicolumn{4}{|c|}{ Full Term $(N=11,354)$} & \multicolumn{4}{|c|}{ Preterm $(N=975)$} & \multicolumn{4}{|c|}{ Total $(N=12,340)$} \\
\hline & \multirow{2}{*}{\multicolumn{2}{|c|}{$\begin{array}{l}\text { BV exposed } \\
N=2198\end{array}$}} & \multirow{2}{*}{\multicolumn{2}{|c|}{$\begin{array}{l}\text { BV unexposed } \\
N=9156\end{array}$}} & \multirow{2}{*}{\multicolumn{2}{|c|}{$\begin{array}{l}\text { BV exposed } \\
N=267\end{array}$}} & \multirow{2}{*}{\multicolumn{2}{|c|}{$\begin{array}{l}\text { BV unexposed } \\
N=708\end{array}$}} & \multirow{2}{*}{\multicolumn{2}{|c|}{$\begin{array}{l}\text { BV exposed } \\
N=2468\end{array}$}} & \multirow{2}{*}{\multicolumn{2}{|c|}{$\begin{array}{l}\text { BV unexposed } \\
N=9872\end{array}$}} \\
\hline & & & & & & & & & & & & \\
\hline & $n$ & $\%$ & $n$ & $\%$ & $n$ & $\%$ & $n$ & $\%$ & $n$ & $\%$ & $n$ & $\%$ \\
\hline \multicolumn{13}{|l|}{ Age (years)* } \\
\hline$<20$ & 324 & 14.7 & 666 & 7.3 & 39 & 14.6 & 56 & 7.9 & 363 & 14.7 & 723 & 7.3 \\
\hline $20-24$ & 784 & 35.7 & 2095 & 22.9 & 79 & 29.6 & 179 & 25.3 & 866 & 35.1 & 2278 & 23.1 \\
\hline $25-29$ & 620 & 28.2 & 2593 & 28.3 & 66 & 24.7 & 166 & 23.5 & 686 & 27.8 & 2760 & 28.0 \\
\hline $30-34$ & 317 & 14.4 & 2375 & 26.0 & 44 & 16.5 & 188 & 26.6 & 361 & 14.6 & 2564 & 26.0 \\
\hline $35+$ & 153 & 7.0 & 1424 & 15.6 & 39 & 14.6 & 119 & 16.8 & 192 & 7.8 & 1544 & 15.6 \\
\hline \multicolumn{13}{|l|}{ Race/Ethnicity* } \\
\hline White & 1268 & 58.8 & 6842 & 71.7 & 152 & 58.9 & 497 & 71.8 & 1422 & 58.8 & 6981 & 71.7 \\
\hline Black & 231 & 10.7 & 416 & 4.6 & 21 & 8.1 & 36 & 5.2 & 252 & 10.4 & 452 & 4.6 \\
\hline Asian & 183 & 8.5 & 939 & 10.4 & 28 & 10.9 & 64 & 9.3 & 212 & 8.8 & 1006 & 10.3 \\
\hline Hispanic & 410 & 19.0 & 979 & 10.8 & 39 & 15.1 & 73 & 10.6 & 449 & 18.6 & 1054 & 10.8 \\
\hline Native American & 62 & 2.9 & 218 & 2.4 & 18 & 7.0 & 22 & 3.2 & 80 & 3.3 & 240 & 2.5 \\
\hline Other & 4 & 0.2 & 9 & 0.1 & 0 & 0.0 & 0 & 0.0 & 4 & 0.2 & 9 & 0.1 \\
\hline \multicolumn{13}{|l|}{ Education* } \\
\hline Less than H.S. & 689 & 31.6 & 1639 & 18.1 & 89 & 34.1 & 148 & 21.4 & 779 & 31.9 & 1791 & 18.4 \\
\hline H.S. grad/some college & 1132 & 51.9 & 4134 & 45.8 & 129 & 49.4 & 323 & 46.6 & 1263 & 51.7 & 4460 & 45.8 \\
\hline College graduate & 360 & 16.5 & 3263 & 36.1 & 43 & 16.5 & 222 & 32.0 & 403 & 16.5 & 3486 & 35.8 \\
\hline Nulliparous* & 3733 & 47.2 & 1035 & 41.4 & 118 & 45.2 & 309 & 45.2 & 1154 & 47.0 & 4045 & 41.7 \\
\hline Cesarean delivery* & 477 & 21.7 & 2479 & 27.1 & 78 & 29.3 & 269 & 38.1 & 555 & 22.5 & 2751 & 27.9 \\
\hline Low Birth Weight $(<2500 \mathrm{~g})^{*}$ & 41 & 1.9 & 139 & 1.5 & 158 & 60.1 & 344 & 49.1 & 199 & 8.1 & 483 & 4.9 \\
\hline Small for gestational age & 227 & 10.3 & 790 & 8.6 & 22 & 8.2 & 76 & 10.7 & 249 & 10.1 & 866 & 8.8 \\
\hline missing & 0 & (0) & 12 & $(0.13)$ & 20 & (7.49) & 15 & $(2.12)$ & 23 & $(0.93)$ & 35 & (0.35) \\
\hline Smoking* & 360 & 16.5 & 921 & 10.1 & 42 & 15.9 & 84 & 12.0 & 404 & 16.5 & 1006 & 10.3 \\
\hline \multicolumn{13}{|l|}{ Kotelchuck Index } \\
\hline Inadequate & 374 & 17.8 & 1203 & 15.2 & 29 & 14.2 & 85 & 16.7 & 403 & 17.5 & 1291 & 15.3 \\
\hline Intermediate & 475 & 22.6 & 1763 & 22.3 & 39 & 19.1 & 76 & 14.9 & 514 & 22.3 & 1839 & 21.8 \\
\hline Adequate & 899 & 42.7 & 3658 & 46.3 & 52 & 25.5 & 150 & 29.5 & 951 & 41.2 & 3808 & 45.2 \\
\hline Adequate Plus & 356 & 16.9 & 1283 & 16.2 & 84 & 41.2 & 198 & 38.9 & 440 & 19.1 & 1481 & 17.6 \\
\hline missing & 94 & (4.3) & 1249 & (13.6) & 63 & (23.6) & 199 & $(28.1)$ & 160 & $(6.5)$ & 1453 & (14.7) \\
\hline$\left.\mathrm{ST}\right|^{*}+$ & 296 & 13.5 & 379 & 4.1 & 34 & 12.7 & 42 & 5.9 & 330 & 13.4 & 422 & 4.3 \\
\hline Maternal comorbiditiesł & 236 & 10.8 & 1022 & 11.3 & 53 & 20.0 & 184 & 26.3 & 289 & 11.7 & 1207 & 12.4 \\
\hline missing & 2 & $(0.1)$ & 92 & (1.0) & 2 & $(0.8)$ & 7 & $(1.0)$ & 5 & $(0.2)$ & 99 & $(1.0)$ \\
\hline Chorioamnionitis* & 62 & 2.8 & 265 & 2.9 & 22 & 8.2 & 41 & 5.8 & 84 & 3.4 & 306 & 3.1 \\
\hline Meconium (moderate/heavy) & 198 & 9.0 & 510 & 5.6 & 6 & 2.3 & 19 & 2.7 & 204 & 8.3 & 530 & 5.4 \\
\hline missing & 4 & $(0.2)$ & 98 & $(1.1)$ & 20 & $(7.5)$ & 26 & (3.7) & 25 & $(1.0)$ & 126 & (1.3) \\
\hline
\end{tabular}

$B V$ bacterial vaginosis; H.S. High School, STI sexually transmitted infections

${ }^{*}$ Missing data not displayed, $<3.5 \%$ in all groups

tsyphilis, gonorrhea, chlamydia, and/or genital herpes

łhypertension, diabetes, and/or pre-eclampsia

Among all infants, preterm birth was $55 \%$ more likely to occur in women with BV (Table 5). Assisted ventilation at birth, admission to NICU, and neonatal sepsis were also associated with BV exposure in the whole cohort. There was an association between BV and 2nd trimester (20-28 weeks gestation) fetal mortality ( $\mathrm{aRR}=10.42,95 \% \mathrm{CI} 3.55,30.61)$. 
Table 2 Associations between bacterial vaginosis and adverse outcomes among full-term infants (37 weeks or greater gestation), Washington State, 2003-2013, adjusted for gestational age, maternal age, and maternal race $(N=11,354)$

\begin{tabular}{|c|c|c|c|c|c|c|c|c|}
\hline & BV ex & & BV u & & $R R$ & $95 \% \mathrm{Cl}$ & aRR & $95 \% \mathrm{Cl}$ \\
\hline & $N=2$ & & $N=9$ & & & & & \\
\hline & $n$ & $\%$ & $n$ & $\%$ & & & & \\
\hline Assisted ventilation at birth & 100 & 4.6 & 331 & 3.6 & 1.26 & $1.01-1.57$ & 1.28 & $1.02-1.61$ \\
\hline Admission to NICU at birth & 89 & 4.1 & 272 & 3.0 & 1.36 & $1.08-1.72$ & 1.42 & $1.11-1.82$ \\
\hline Neonatal sepsis & 48 & 2.2 & 126 & 1.4 & 1.59 & $1.14-2.21$ & 1.60 & $1.13-2.27$ \\
\hline Fetal Mortality & 3 & 0.1 & 13 & 0.1 & 0.96 & $0.27-3.37$ & $1.15^{*}$ & $0.27-4.96$ \\
\hline Infant mortality & 4 & 0.2 & 24 & 0.3 & 0.69 & $0.24-2.00$ & 0.39 & $0.12-1.28$ \\
\hline
\end{tabular}

$B V$ bacterial vaginosis, $R R$ risk ratio, $a R R$ adjusted risk ratio, $C l$ confidence interval, NICU neonatal intensive care unit

*further adjusted for presence of sexually transmitted infections (syphilis, gonorrhea, chlamydia, and/or genital herpes)

\section{Discussion}

Consistent with prior research, we found a strong association between BV and risk for preterm birth [3, 5, $10,11,13]$. More importantly, our primary study goal was to assess term outcomes. We hypothesized that BV would increase the risk for adverse neonatal outcomes, even among infants born full-term. We found an association between BV and an increased risk of neonatal assisted ventilation/respiratory distress, admission to NICU, and neonatal sepsis in the full cohort of term and preterm infants, similar to a prior study [6]. But, notably these findings persisted when analyses were restricted to only term deliveries.
Our data demonstrate an association between BV during pregnancy and poor neonatal outcomes at term that has only been hinted at previously [4]. We had hypothesized that poor neonatal outcomes could be due to ascending infection during pregnancy that might increase risks of chorioamnionitis or poor fetal growth, which in turn might increase the risk of poor neonatal outcomes. Meta-analyses previously showed a trend for increased risk of neonatal sepsis associated with BV in infants of all gestational ages, but results were nonsignificant and sample sizes limited with an inability to fully explore term outcomes $[3,5]$. Data from a single study, with a small sample of 151 term BV exposures

Table 3 Associations between bacterial vaginosis and adverse outcomes among full-term infants (37 weeks or greater gestation), Washington State, 2003-2013 ( $N=11,354)$, adjusted for gestational age, maternal age, and maternal race, and additionally adjusted for the presence of chorioamnionitis or meconium

\begin{tabular}{|c|c|c|c|c|c|c|}
\hline & \multicolumn{2}{|c|}{ BV exposed } & \multicolumn{2}{|c|}{ BV unexposed } & \multirow[t]{3}{*}{$\mathrm{aRR}$} & \multirow[t]{3}{*}{$95 \% \mathrm{Cl}$} \\
\hline & \multicolumn{2}{|c|}{$N=2198$} & \multicolumn{2}{|c|}{$N=9156$} & & \\
\hline & $n$ & $\%$ & $n$ & $\%$ & & \\
\hline Assisted ventilation at birth & 98 & 4.5 & 328 & 3.6 & 1.28 & $1.02-1.61$ \\
\hline additionally adjusted for chorioamnionitis & 98 & 4.5 & 328 & 3.6 & 1.28 & $1.02-1.61$ \\
\hline additionally adjusted for meconium & 98 & 4.5 & 328 & 3.7 & 1.22 & $0.97-1.53$ \\
\hline Admission to NICU at birth & 88 & 4.1 & 269 & 3.0 & 1.42 & $1.11-1.82$ \\
\hline additionally adjusted for chorioamnionitis & 88 & 4.1 & 269 & 3.0 & 1.45 & $1.13-1.85$ \\
\hline additionally adjusted for meconium & 88 & 4.1 & 267 & 3.0 & 1.34 & $1.05-1.72$ \\
\hline Neonatal sepsis & 48 & 2.2 & 125 & 1.4 & 1.60 & $1.13-2.27$ \\
\hline additionally adjusted for chorioamnionitis & 48 & 2.2 & 125 & 1.4 & 1.67 & $1.19-2.35$ \\
\hline additionally adjusted for meconium & 48 & 2.2 & 125 & 1.4 & 1.51 & $1.06-2.14$ \\
\hline Fetal Mortality & 3 & 0.1 & 12 & 0.1 & $1.15^{*}$ & $0.27-4.96$ \\
\hline additionally adjusted for chorioamnionitis & 3 & 0.1 & 12 & 0.1 & $1.14^{*}$ & $0.27-4.88$ \\
\hline additionally adjusted for meconium & 0 & 0.0 & 3 & 0.0 & - & - \\
\hline Infant mortality & 3 & 0.1 & 24 & 0.3 & 0.39 & $0.12-1.28$ \\
\hline additionally adjusted for chorioamnionitis & 3 & 0.1 & 24 & 0.3 & 0.39 & $0.12-1.27$ \\
\hline additionally adjusted for meconium & 3 & 0.1 & 23 & 0.3 & 0.40 & $0.12-1.34$ \\
\hline
\end{tabular}

$B V$ bacterial vaginosis, aRR adjusted risk ratio, $C l$ confidence interval, NICU neonatal intensive care unit

*further adjusted for presence of sexually transmitted infections (syphilis, gonorrhea, chlamydia, and/or genital herpes) 
Table 4 Associations between bacterial vaginosis and adverse outcomes among preterm infants (less than 37 weeks gestation), Washington State, 2003-2013, adjusted for gestational age, maternal age, and maternal race $(N=975)$

\begin{tabular}{|c|c|c|c|c|c|c|c|c|}
\hline & BV ex & & BV ur & & $\mathrm{RR}$ & $95 \% \mathrm{Cl}$ & $\mathrm{aRR}$ & $95 \% \mathrm{Cl}$ \\
\hline & $N=2$ & & $N=7$ & & & & & \\
\hline & $n$ & $\%$ & $n$ & $\%$ & & & & \\
\hline Assisted ventilation at birth & 51 & 19.1 & 94 & 13.3 & 1.44 & $1.05-1.96$ & 1.23 & $0.89-1.73$ \\
\hline Admission to NICU at birth & 124 & 50.4 & 246 & 36.0 & 1.40 & $1.20-1.64$ & 1.24 & $1.04-1.46$ \\
\hline Neonatal sepsis & 47 & 17.6 & 82 & 11.6 & 1.52 & $1.09-2.11$ & 1.31 & $0.91-1.89$ \\
\hline Fetal Mortality & 21 & 7.9 & 21 & 3.0 & 2.65 & $1.47-4.78$ & 1.25 & $0.67-2.33$ \\
\hline Infant mortality & 17 & 6.9 & 21 & 3.1 & 2.26 & $1.21-4.22$ & 1.10 & $0.66-1.84$ \\
\hline
\end{tabular}

$B V$ bacterial vaginosis, $R R$ risk ratio, $a R R$ adjusted risk ratio, $C l$ confidence interval, NICU neonatal intensive care unit

and 6 instances of infectious morbidity, suggests a modest association between infectious morbidity and BV exposure early in pregnancy among full-term infants; however, this association was not formally examined [4]. BV has been associated with chorioamnionitis in primarily preterm cohorts $[14,15]$, and chorioamnionitis is associated with neonatal sepsis in both term and preterm infants [16, 17]. Our study of 12,340 infants showed significant associations between BV and neonatal sepsis, both in the complete cohort and in the subset of full-term infants that included 2,198 BV-exposed mother/infant pairs. BV-exposed women delivering at term also had higher rates of meconium, which has been associated with in-utero bacteria [18] and worse neonatal outcomes [19]. However, when the presence of meconium and/or chorioamnionitis were included in our models, the risk for adverse outcomes persisted, suggesting that the association between BV and neonatal compromise is not due to meconium aspiration or the direct effects of chorioamnionitis. BV is associated with upper genital tract infection in both pregnant [20] and non-pregnant [21] women, thus sub-clinical infection could be one mechanism for the poor neonatal outcomes observed.
Others have not evaluated full-term births for the association of BV with SGA or LBW. Among full-term infants in our cohort, BV-exposed infants were more likely to be SGA, but not more likely than unexposed infants to have LBW. In our full cohort, BV-exposed infants were more likely to be SGA or LBW, confirming previous reports of this association [15, 22, 23]. In other studies among preterm infants, BV has been associated with LBW [1]. In a cohort of late preterm (>33 weeks) and term infants, SGA was associated with increased NICU admission, low Apgar scores and composite neonatal morbidity [24]. In our study, SGA infants were at greater risk of NICU admission when born preterm, and greater risk of neonatal sepsis when born full-term, but these increased risks were not statistically different from LGA and AGA infants.

The increased risk of NICU admissions and respiratory distress among full-term infants exposed to BV that we observed in our cohort has not been previously described, to our knowledge. In a small cohort of preterm infants, the proportions of infants with respiratory distress, requirement of intermittent positive pressure ventilation, admission to NICU, and NICU stays over two days was higher among BV exposed than among BV-unexposed

Table 5 Associations between bacterial vaginosis and adverse outcomes among all infants, Washington State, 2003-2013, adjusted for maternal age and race $(N=12,340)$

\begin{tabular}{|c|c|c|c|c|c|c|c|c|}
\hline & \multirow{2}{*}{\multicolumn{2}{|c|}{$\frac{B V \text { exposed }}{N=2468}$}} & \multirow{2}{*}{\multicolumn{2}{|c|}{$\frac{\text { BV unexposed }}{N=9872}$}} & \multirow[t]{3}{*}{$\mathrm{RR}$} & \multirow[t]{3}{*}{$95 \% \mathrm{Cl}$} & \multirow[t]{3}{*}{ aRR } & \multirow[t]{3}{*}{$95 \% \mathrm{Cl}$} \\
\hline & & & & & & & & \\
\hline & $\bar{n}$ & $\%$ & $\bar{n}$ & $\%$ & & & & \\
\hline Preterm birth & 267 & 10.8 & 708 & 7.2 & 1.51 & $1.32-1.72$ & 1.55 & $1.34-1.78$ \\
\hline Assisted ventilation at birth & 151 & 6.1 & 425 & 4.3 & 1.42 & $1.19-1.70$ & 1.45 & $1.21-1.75$ \\
\hline Admission to NICU at birth & 213 & 8.7 & 519 & 5.3 & 1.65 & $1.42-1.92$ & 1.73 & $1.47-2.03$ \\
\hline Neonatal sepsis & 95 & 3.9 & 209 & 2.1 & 1.82 & $1.43-2.31$ & 1.86 & $1.44-2.41$ \\
\hline Fetal Mortality & 25 & 1.0 & 35 & 0.4 & 2.86 & $1.71-4.76$ & $2.79^{*}$ & $1.54-5.05$ \\
\hline 2nd trimester & 16 & 0.7 & 7 & 0.1 & 12.22 & $4.29-34.79$ & $10.42^{*}$ & $3.55-30.61$ \\
\hline 3rd trimester & 9 & 0.4 & 28 & 0.3 & 1.49 & $0.65-3.40$ & $1.31^{*}$ & $0.55-3.11$ \\
\hline Infant mortality & 21 & 0.9 & 45 & 0.5 & 1.89 & $1.12-3.15$ & 1.61 & $0.90-2.90$ \\
\hline
\end{tabular}

$B V$ bacterial vaginosis, $R R$ risk ratio, $a R R$ adjusted risk ratio, $C l$ confidence interval, $N I C U$ neonatal intensive care unit

*further adjusted for presence of a maternal comorbidity (hypertension, diabetes, and/or pre-eclampsia) 
pregnancies (uncontrolled analyses) [6]. We confirmed the association between BV and NICU admission in preterm infants, controlling for gestational age and several possible confounders, strengthening the likelihood that this association is biologically true.

We did not find an increased risk for term perinatal mortality associated with BV and, to our knowledge, this has not been studied previously. BV has not been associated with perinatal mortality in previous meta-analyses of primarily preterm cohorts [3]. Perinatal mortality was not associated with overall fetal or infant mortality in our full cohort. However, when we evaluated mortality by trimester, the risk of 2 nd trimester fetal mortality was increased, supporting meta-analyses that reported a 6-fold increased risk for loss between 14-24 weeks in women diagnosed with BV during early pregnancy [3].

Our study has strengths and limitations. It was large, population-based, and rich in covariates, with little missing data. While birth certificate sensitivity is poor for some variables $[8,25]$, we increased ascertainment of exposures and outcomes by using both birth certificates and linked hospital records. Since routine screening for BV is not standard of care, cases identified were likely symptomatic, which may limit this study's findings to cases of symptomatic BV. While asymptomatic cases may be under-diagnosed, including asymptomatic BV-exposed mothers among the unexposed would bias results towards the null. We did not have data on BV treatment in exposed women or the trimester that BV was diagnosed. If $\mathrm{BV}$ treatment tempers the increased risk of the poor neonatal outcomes associated with BV, associations may be even greater than reported here. Furthermore, associations may differ according to the timing of BV treatment. Further studies are needed to address these questions. Additionally, $68 \%$ of the women were White, limiting the generalizability of our findings. A large proportion of women were nulliparous. But as all data are de-identified, mothers who gave birth more than once during the study period may have been included multiple times, potentially introducing a clustering bias we are unable to address. Lastly, our study shows an association, but cannot confirm a causal relationship between $\mathrm{BV}$ and poor outcomes among term deliveries.

\section{Conclusions}

BV during pregnancy appears to increase the risk for adverse neonatal outcomes through mechanisms independent of BV's effect on timing of delivery. These findings may have significant clinical implications if confirmed by other studies, but several questions remain, including the importance of timing of the exposure and the mechanism for these associations. While treatment of BV during pregnancy has not succeeded in reducing preterm birth [26, 27], treatments targeted specifically at improving term neonatal outcomes have not been explored as thoroughly. The Maternal Fetal Medicine Unit's treatment trial for asymptomatic BV between 16 and 24 weeks did not show a difference in birthweight, NICU admission, neonatal sepsis, or neonatal death, though data were only shown for the first outcome. The sample size of the trial was only 1,953 , thus it may not have had adequate power to detect differences in these uncommon outcomes [27]. A Cochrane review [28] of seven randomized clinical trials on antibiotic prophylaxis during pregnancy for women at high risk of preterm birth had inadequate power to study the effect of prophylaxis on neonatal sepsis, did not restrict analyses to women with BV, did not report on NICU admission, and did not focus on term deliveries. There are very few prior studies directly relevant to our findings - an increased risk of neonatal assisted ventilation/respiratory distress, admission to $\mathrm{NICU}$, and neonatal sepsis among BV exposed infants born at term. Our findings suggest that any study evaluating the vaginal microbiota in pregnancy should include neonatal outcomes as an endpoint, and expand our understanding of BV associated outcomes in preterm infants to term deliveries.

\section{Abbreviations \\ AGA: Average for gestational age; aRR: Adjusted relative risk; BERD: Birth Events Record Database; BV: Bacterial vaginosis; CHARS: Comprehensive Hospital Abstract Reporting System; ICD: International Classification of Disease; LBW: Low birth weight; LGA: Large for gestational age; NICU: Neonatal intensive care unit; RR: Relative risk; SGA: Small for gestational age; STI: Sexually transmitted infection}

\section{Acknowledgements}

The authors wish to thank the Washington State Department of Health for data access, Mr. Bill O'Brien for programming and data management and Dr. Steve Hawes for guidance with our analyses.

\section{Funding}

AD was supported by an NSF Graduate Research Fellowship (DGE-1256082) and an NIH Interdisciplinary Training Grant (T32 CA080416). These funders played no role in the study design, data collection, analysis, writing, or decision to publish.

\section{Availability of data and material}

Data from this study will not be publicly available. Data were obtained from the Washington State Department of health under condition that data would be destroyed after completion of the project.

Authors' contributions

AD and TF designed the study, performed the analyses, analyzed the results, and wrote the manuscript. SR and CM made major contributions to the interpretation of the data and writing of the manuscript. All authors read and approved the final manuscript.

\section{Competing interests}

CM sits on a scientific advisory board for Perrigo Pharmaceuticals. The remaining authors declare no conflicts of interest.

Ethics approval and consent to participate

All data were de-identified, and the study was determined to be exempt from review by the Washington State Institutional Review Board. 


\section{Author details}

'Department of Epidemiology, University of Washington School of Public Health, 1959 NE Pacific Street Health Sciences Bldg, Seattle, WA 98195, USA. 2University of Washington, Molecular \& Cellular Biology Program, 1959 NE Pacific St, Seattle, WA 98195, USA. ${ }^{3}$ Fred Hutchinson Cancer Research Center, 1100 Fairview Ave N, Seattle, WA 98109, USA. ${ }^{4}$ Harborview Medical Center, 325 Ninth Ave, Seattle, WA 98104, USA. ${ }^{5}$ Vincent Center for Reproductive Biology, Massachusetts General Hospital, 55 Fruit Street, Boston, MA 02114, USA. ${ }^{6}$ Harvard Medical School, 25 Shattuck St, Boston, MA 02115, USA.

Received: 25 June 2016 Accepted: 6 September 2016 Published online: 22 September 2016

\section{References}

1. Hillier SL, Nugent RP, Eschenbach DA, Krohn MA, Gibbs RS, Martin DH, Cotch MF, Edelman R, Pastorek 2nd JG, Rao AV, et al. Association between bacterial vaginosis and preterm delivery of a low-birth-weight infant. The Vaginal Infections and Prematurity Study Group. N Engl J Med. 1995;333(26):1737-42.

2. Guise J-M, Mahon SM, Aickin M, Helfand M, Peipert JF, Westhoff C. Screening for bacterial vaginosis in pregnancy. Am J Prev Med. 2001;20(3):62-72.

3. Leitich $\mathrm{H}$, Kiss $\mathrm{H}$. Asymptomatic bacterial vaginosis and intermediate flora as risk factors for adverse pregnancy outcome. Best Pract Res Clin Obstet Gynaecol. 2007:21(3):375-90.

4. Kurki T, Sivonen A, Renkonen OV, Savia E, Ylikorkala O. Bacterial vaginosis in early pregnancy and pregnancy outcome. Obstet Gynecol. 1992;80(2):173-7.

5. Leitich H, Bodner-Adler B, Brunbauer M, Kaider A, Egarter C, Husslein P. Bacterial vaginosis as a risk factor for preterm delivery: a meta-analysis. Am J Obstet Gynecol. 2003;189(1):139-47.

6. Laxmi U, Agrawal S, Raghunandan C, Randhawa VS, Saili A. Association of bacterial vaginosis with adverse fetomaternal outcome in women with spontaneous preterm labor: a prospective cohort study. J Matern Fetal Neonatal Med. 2012;25(1):64-7.

7. Herman A, McCarthy B, Bakewell J, Ward R, Mueller B, Maconochie N, Read A, Zadka P, Skjaerven R. Data linkage methods used in maternally-linked birth and infant death surveillance data sets from the United States (Georgia, Missouri, Utah and Washington State), Israel, Norway, Scotland and Western Australia. Paediatr Perinat Epidemiol. 1997;11(S1):5-22.

8. Lydon-Rochelle MT, Holt VL, Nelson JC, Cardenas V, Gardella C, Easterling TR, Callaghan WM. Accuracy of reporting maternal in-hospital diagnoses and intrapartum procedures in Washington State linked birth records. Paediatr Perinat Epidemiol. 2005;19(6):460-71.

9. Goff SL, Pekow PS, Markenson G, Knee A, Chasan-Taber L, Lindenauer PK. Validity of using ICD-9-CM codes to identify selected categories of obstetric complications, procedures and co-morbidities. Paediatr Perinat Epidemiol. 2012;26(5):421-9.

10. Chaim W, Mazor M, Leiberman JR. The relationship between bacterial vaginosis and preterm birth. Rev Arch Gynecol Obstet. 1997:259(2):51-8.

11. Manns-James L. Bacterial vaginosis and preterm birth. J Midwifery Womens Health. 2011:56(6):575-83.

12. Lipsky S, Easterling TR, Holt VL, Critchlow CW. Detecting small for gestational age infants: the development of a population-based reference for Washington State. Am J Perinatol. 2005;22(8):405-12.

13. Nelson DB, Macones G. Bacterial vaginosis in pregnancy: current findings and future directions. Epidemiol Rev. 2002;24(2):102-8.

14. Kekki M, Kurki T, Pelkonen J, Kurkinen-Raty M, Cacciatore B, Paavonen J. Vaginal clindamycin in preventing preterm birth and peripartal infections in asymptomatic women with bacterial vaginosis: a randomized, controlled trial. Obstet Gynecol. 2001:97(5 Pt 1):643-8.

15. Svare JA, Schmidt $H$, Hansen BB, Lose G. Bacterial vaginosis in a cohort of Danish pregnant women: prevalence and relationship with preterm delivery, low birthweight and perinatal infections. BJOG. 2006;113(12):1419-25.

16. Alexander JM, McIntire DM, Leveno KJ. Chorioamnionitis and the prognosis for term infants. Obstet Gynecol. 1999:94(2):274-8.

17. Soraisham AS, Singhal N, McMillan DD, Sauve RS, Lee SK, Canadian Neonatal N. A multicenter study on the clinical outcome of chorioamnionitis in preterm infants. Am J Obstet Gynecol. 2009;200(4):372. e371-376.

18. Romero R, Yoon BH, Chaemsaithong P, Cortez J, Park CW, Gonzalez R, Behnke E, Hassan SS, Chaiworapongsa T, Yeo L. Bacteria and endotoxin in meconium-stained amniotic fluid at term: could intra-amniotic infection cause meconium passage? J Matern Fetal Neonatal Med. 2014;27(8):775-88.
19. Hiersch L, Krispin E, Aviram A, Wiznitzer A, Yogev Y, Ashwal E. Effect of meconium-stained amniotic fluid on perinatal complications in low-risk pregnancies at term. Am J Perinatol. 2015.

20. Newton ER, Piper J, Peairs W. Bacterial vaginosis and intraamniotic infection. Am J Obstet Gynecol. 1997;176(3):672-7.

21. Andrews WW, Hauth JC, Cliver SP, Conner MG, Goldenberg RL, Goepfert AR. Association of asymptomatic bacterial vaginosis with endometrial microbial colonization and plasma cell endometritis in nonpregnant women. Am J Obstet Gynecol. 2006;195(6):1611-6.

22. Thorsen P, Vogel I, Olsen J, Jeune B, Westergaard JG, Jacobsson B, Moller BR Bacterial vaginosis in early pregnancy is associated with low birth weight and small for gestational age, but not with spontaneous preterm birth: a population-based study on Danish women. J Matern Fetal Neonatal Med. 2006;19(1):1-7.

23. Slyker JA, Patterson J, Ambler G, Richardson BA, Maleche-Obimbo E, Bosire R, Mbori-Ngacha D, Farquhar C, John-Stewart G. Correlates and outcomes of preterm birth, low birth weight, and small for gestational age in HIVexposed uninfected infants. BMC Pregnancy Childbirth. 2014;14:7.

24. Anderson NH, Sadler LC, McKinlay CJ, McCowan LM. INTERGROWTH 21st versus customized birthweight standards for identification of perinatal mortality and morbidity. Am J Obstet Gynecol. 2015.

25. Bradford HM, Cardenas V, Camacho-Carr K, Lydon-Rochelle MT. Accuracy of birth certificate and hospital discharge data: a certified nurse-midwife and physician comparison. Matern Child Health J. 2007;11(6):540-8.

26. Brocklehurst P, Gordon A, Heatley E, Milan SJ. Antibiotics for treating bacterial vaginosis in pregnancy. Cochrane Database Syst Rev. 2013;1:CD000262.

27. Carey JC, Klebanoff MA, Hauth JC, Hillier SL, Thom EA, Ernest JM, Heine RP, Nugent RP, Fischer ML, Leveno KJ, et al. Metronidazole to prevent preterm delivery in pregnant women with asymptomatic bacterial vaginosis. National Institute of Child Health and Human Development Network of Maternal-Fetal Medicine Units. N Engl J Med. 2000;342(8):534-40.

28. Thinkhamrop J, Hofmeyr GJ, Adetoro O, Lumbiganon P, Ota E. Antibiotic prophylaxis during the second and third trimester to reduce adverse pregnancy outcomes and morbidity. Cochrane Database Syst Rev. 2015;6:CD002250.

\section{Submit your next manuscript to BioMed Central and we will help you at every step:}

- We accept pre-submission inquiries

- Our selector tool helps you to find the most relevant journal

- We provide round the clock customer support

- Convenient online submission

- Thorough peer review

- Inclusion in PubMed and all major indexing services

- Maximum visibility for your research

Submit your manuscript at www.biomedcentral.com/submit
) Biomed Central 